\title{
Perfil dos pacientes em atendimento na Liga de Doença Renal Crônica
}

\author{
Ana Letícia Fornazieri Darcie', Jessica Kazumi Okuma ${ }^{1}$, Bruno Figueiredo Pereira ${ }^{1}$, \\ Barbara Helena Monteiro ${ }^{1}$, Raif Restivo Simão ${ }^{1}$, Rodrigo Akira Watanabe ${ }^{1}$, Hugo Abensur ${ }^{2}$
}

Darcie ALF, Okuma JK, Pereira BF, Monteiro BH, Simão RR, Watanabe RA, Abensur H. Perfil dos pacientes em atendimento na Liga de Doença Renal Crônica. Rev Med (São Paulo). 2015 jan.-mar.;94(1):73-4.

\section{INTRODUÇÃO}

Caracterizada pela perda lenta e progressiva da função renal, a Doença Renal Crônica (DRC) é causada principalmente por diabetes mellitus e hipertensão arterial sistêmica. Várias são suas consequências para o organismo, como anemia, hiperparatireoidismo secundário e distúrbios hidroeletrolíticos. Os pacientes são atendidos na Liga até serem encaminhados, em fases mais avançadas, para tratamento dialítico ou transplante renal.

\section{OBJETIVOS}

Apresentar as características epidemiológicas, clínicas e laboratoriais dos pacientes da Liga e identificar as principais causas, as complicações e o ritmo de progressão da DRC.

\section{METODOLOGIA}

Coletaram-se os dados de prontuário de todos os pacientes atendidos na Liga em 2013.

\section{Descrição da Liga}

Administrada por dois diretores e um presidente, acadêmicos de Medicina, a Liga conta com vinte e quatro residentes de Nefrologia, dois preceptores, dois supervisores, duas fisioterapeutas, uma psicóloga, duas nutricionistas e uma farmacêutica clínica. Acompanham as atividades catorze acadêmicos de Medicina e quatro de Nutrição.

A Liga objetiva retardar a progressão da DRC e tratar suas complicações. São matriculados pacientes adultos com diagnóstico de DRC, excetuando-se aqueles com clearance de creatinina menor que $15 \mathrm{ml} / \mathrm{min}$. Os atendimentos, supervisionados, ocorrem no ambulatório de Nefrologia, na enfermaria e na unidade de diálise. Os alunos aprendem sobre diagnóstico etiológico e estadiamento da DRC, identificação e manejo de suas complicações e retardo da progressão. Os casos mais representativos são discutidos com os supervisores e os demais profissionais da saúde. Além das complicações da própria doença, são abordadas as múltiplas comorbidades dos pacientes.

Sob orientação dos supervisores, atividades de pesquisa são desenvolvidas e apresentadas em eventos de grande prestígio.

\footnotetext{
$2^{\circ}$ lugar Prêmio Painéis - Liga Acadêmica no 33 COMU - Congresso Médico Universitário da FMUSP, SP, 31 de out. a 02 de nov. de 2014.

1. Acadêmicos de Medicina da Faculdade de Medicina da Universidade de São Paulo.

2. Orientador, Faculdade de Medicina da Universidade de São Paulo.
} 


\section{RESULTADOS}

Foram atendidos sessenta pacientes em 2013. A maioria é do sexo masculino $(73,3 \%)$, de etnia branca (85\%), com média de idade de $67 \pm 14$ anos e IMC médio de $28,2 \pm 5,14 \mathrm{~kg} / \mathrm{m}^{2}$.

A PAS média é $131,85 \pm 20,13 \mathrm{mmHg}$ e a PAD, $71,27 \pm 11,98 \mathrm{mmHg}$. Cinquenta por cento dos pacientes são hipertensos, $45 \%$ dislipidêmicos e $41,6 \%$ diabéticos.

Nefroesclerose hipertensiva corresponde a $66,6 \%$ dos casos de DRC, seguida de nefropatia diabética $(13,72 \%)$. Os pacientes encontram-se majoritariamente entre os estágios III (40\%) e IV (36,6\%) da doença, com clearance de creatinina entre 30 e $89 \mathrm{ml} / \mathrm{min} .58,33 \%$ dos pacientes têm hiperparatireoidismo secundário; 36,7\%, gota; $21,6 \%$, proteinuria e $10 \%$, anemia.

A variação da função renal média é $+0,148 \mathrm{ml} /$ $\mathrm{min} / 1,73 \mathrm{~m}^{2}$ e apenas $6,6 \%$ dos pacientes apresentam progressão rápida da doença (perda anual $>5 \mathrm{ml} /$ $\left.\min / 1,73 \mathrm{~m}^{2}\right)$.

\section{DISCUSSÃO}

Contrariando estudos anteriores, observamos franco predomínio de nefroesclerose hipertensiva como etiologia da DRC, o que pode estar relacionado a um viés de seleção. Como a nefropatia diabética apresenta progressão mais rápida, muitos casos seriam excluídos pelos critérios de admissão da Liga. A variação da função renal média positiva e baixa porcentagem de rápidos progressores indicam que, uma vez estabilizados clinicamente na Liga, há melhora da função renal, reforçando a importância do atendimento multidisciplinar.

\section{DESAFIOS}

Apesar de a Liga atuar no Dia Mundial do Rim, consideramos sua participação em políticas de prevenção ainda limitada, sendo uma meta sua ampliação. Objetivase também criar mais atividades didáticas para os acadêmicos da Liga. 